\title{
DOUTRINAS QUINHENTISTAS: ASSIDUIDADES E ALOMORFIAS ENTRE LUTERANISMO E ANGLICANISMO
}

\author{
DOUTRINAS QUINHENTISTAS: ASIDUIDADES Y ALOMORFIAS ENTRE \\ LUTERANISMO Y ANGLICANISMO
}

\author{
QUINHENTIST DOCTRINES: ASSUMPTIONS AND ALOMORPHIES \\ BETWEEN LUTERANISM AND ANGLICANISM
}

RESUMO: A conjuntura quinhentista comporta um ínterim de explícitas alomorfias institucionais, aquando de albergar o ascendente fortalecimento do arquétipo estatal europeu e o reformismo protestante. Concomitante a tal arcabouço contextual, suscita-se que a religiosidade aufere assiduidade, mediante a qual a proeminência do metafísico permanece explícita. Ademais, o anticlericalismo quinhentista corroborara notoriedade, intento que fundamentara amplamente o arcabouço reformista. Díspar das homogeneizações doutrinárias, compete ao historiógrafo o ideário de empreender a profícua distinção das ideologias luterana e anglicana, as quais suscitam notórias divergências idearias. Por conseguinte, visar-se-á averiguar as disparidades intrínsecas ao luteranismo e ao anglicanismo, atentando-se para as assiduidade e alomorfias doutrinárias.

PALAVRAS-CHAVE: História comparada. Ideário luterano. Reforma anglicana.

RESUMEN: La coyuntura quinhentista comporta un ínterin de explícitas alomorfismo institucional, en el momento de albergar el ascendente fortalecimiento del arquetipo estatal europeo y el reformismo protestante. Concomitante a tal estructura contextual, se suscita que la religiosidad asume asiduidad, mediante la cual la prominencia del metafísico permanece explícita. Además, el anticlericalismo quinhentista corroboró notoriedad, intento que fundamentara ampliamente el armazón reformista. En el caso de las homogeneizaciones doctrinales, corresponde al historiógrafo el ideario de emprender la provechosa distinción de las ideologías luterana y anglicana, las cuales suscitan notorias divergencias ideales. Por consiguiente, se buscará averiguar las disparidades intrínsecas al luteranismo y al anglicanismo, atentándose para la asiduidad y alomorfías doctrinales.

PALABRAS CLAVE: Historia comparada. Ideario luterano. Reforma anglicana.

ABSTRACT: The sixteenth-century conjuncture entails an interim of explicit institutional allomorphs, when it accommodates the ascending strengthening of the European state archetype and Protestant reformism. Concomitant with such a contextual framework, it is argued that religiosity assumes assiduity, through a prominence of the metaphysician remains

1 Universidade Estadual de Maringá (Uem), Maringá - PR - Brasil. Graduanda em História. E-mail: gio_mantovani@hotmail.com. 
explicit. In addition, the anticlericalism sixteenth century corroborated notoriety, intent that fundamentally the reformist framework. Disparate from doctrinal homogenizations, competing with the historiographer of the ideology of print and profession distinction of Lutheran and Anglican ideologies, as they raise notorious ideological divergences. Therefore, it will be sought to ascertain intrinsic disparities to Lutheranism and Anglicanism, paying attention to assiduity and doctrinal allomorphisms.

KEYWORDS: Comparative history. Lutheran ideology. Anglican reform.

\title{
Introdução
}

\begin{abstract}
O quadripartismo tem como resultado privilegiar o papel do Ocidente na história do mundo e reduzir quantitativa e qualitativamente o lugar dos povos não europeus na evolução universal. Por essa razão, faz parte do aparelho intelectual do imperialismo [...] Esse quadripartismo, todavia, já é inadequado no plano intelectual, inclusive para a Europa e até no interior do discurso histórico clássico. Ele recorta em partes arbitrárias certas zonas históricas homogêneas e originais [...]. O quadripartismo relega a segundo plano os fenômenos mais interessantes, as mudanças profundas, os elos históricos [...] E, finalmente, chega-se a uma verdadeira doutrinação. Um historiador acaba por se convencer de que só é competente nas sacrossantas categorias de base: será proibida toda reflexão geral e comparada. (CHESNEAUX, 1995, p. 95-97).
\end{abstract}

Concernentemente ao quadripartismo amiúde corroborado pela historiografia ocidental, infere-se que tal obduração cronológica culmina em explícitas vicissitudes à profícua apreensão do passado humano. Homogeneizações irrisórias auferem notoriedade ante a sistemática generalização de temporalidades regionalmente cabíveis, aquando de a academia universalizar arquétipos cronológicos cuja aplicabilidade amiúde restringe-se à Europa. Infere-se, por conseguinte, que tais categorias temporais impõem-se sobre as fainas ocidentais sob o intuito de categorizá-las e delimitá-las. Concomitantemente, “[...] as barreiras têm sido vistas como obstáculos à compreensão adequada do que se encontra a um e outro lado delas. " (LOVEJOY, 2000, p. 129; tradução nossa²). Ademais, a obduração quadripartite suscita empecilhos para a profícua execução da longa temporalidade braudeliana, sobretudo no que tange às mentalidades. Notoriamente, confere-se hodierna licitude e imprescindibilidade ao historiógrafo intrinsecamente vinculado aos exames tangíveis à extensa temporalidade, o qual procede a uma ampla secularização analítica (BRAUDEL, 1990, p. 10). Por conseguinte, compete às fainas usufruir de cronologias condizentes à temática suscitada, em detrimento a

${ }^{2}[\ldots]$ las barreras han sido vistas como obstáculos a la compresión adecuada de lo que se encuentra a uno y otro lado de ellas". 
arquétipos homogeneizantes precedentemente formulados. Concerne ao historiógrafo transcender tal rigidez quadripartite a fim de que verifique as assiduidades mentais, refutando discussões acerca do cunho medieval ou moderno da centúria quinhentista.

A segunda abordagem é mais tentadora e mais próxima da realidade. Consistiria em modificar a periodização clássica e estabelecer como princípio que, de meados da Idade Média ao final do século XVII, não houve mudança real das mentalidades profundas. [...] Isso equivaleria a dizer que a periodização da história política, social, econômica, e até cultural, não conviria à história das mentalidades. (ARIÈS; DUBY, 2009, p. 11).

O ínterim concernente à centúria quinhentista alberga uma conjuntura na qual a religiosidade aufere preeminência na mentalidade europeia. Refuta-se a existência do hodierno conceito de incredulidade e ateísmo. A imprescindibilidade do âmbito metafísico corrobora notória assiduidade concernente às centúrias precedentes, aquando de auferir concomitância a intentos eminentemente anticlericais. Ratifica-se, notoriamente, que o quadripartismo mostra-se explicitamente irrisório a fim de propiciar apreensões profícuas de tal temática. Por conseguinte, exames concernentes à religiosidade quinhentista demandam de exumações que transcendam tal periodização clássica. Concomitantemente, axiomas consonantes permanecem implicitamente corroborados no consagrado $O$ problema da incredulidade no século XVI, aquando de L. Febvre suscitar a assiduidade da proeminência do metafísico na conjuntura quinhentista. $\mathrm{O}$ arcabouço ideológico cristão auferia preeminência no quotidiano e na mentalidade quinhentista, transcendendo o ínterim social e integrando a vida privada (FEBVRE, 2009, p. 291; HALE, 1971, p. 178). O ideário de cunho cristão permeava explicitamente os paradigmas europeus, fundamentando as mentalidades e a sociabilidade. Em tautocronia, "O aspecto físico das cidades, vilas e aldeias era dominado pelas igrejas. Não havia multidão, nem estrada de intenso tráfego onde não surgissem os hábitos do clero, os crucifixos e os relicários." (HALE, 1971, p. 179). Infere-se, por conseguinte, que a conjuntura secular permanecia impregnada pela observância cristã.

[...] queiramos ou não, o clima de nossas sociedades ocidentais é sempre, profundamente, um clima cristão. Outrora, no século XVI, ainda mais: o cristianismo era o próprio ar que se respirava no que chamamos a Europa e que era a cristandade. Era uma atmosfera na qual o homem vivia sua vida, toda a sua vida - e não apenas sua vida intelectual, mas também sua vida privada de atos múltiplos, sua vida pública de ocupações diversas, sua vida profissional, qualquer que fosse seu âmbito. [...] Se se quisesse ou não, se se percebesse claramente ou não, as pessoas achavam-se mergulhadas desde o nascimento num banho de cristianismo, do qual não se evadiam nem mesmo na morte: pois essa morte era cristã necessária e socialmente, pelos ritos a 
que ninguém podia furtar-se [...]. Do nascimento à morte, estendia-se toda uma cadeia de cerimônias, de tradições, de costumes, de práticas - que, sendo todos cristãos ou cristianizados, atavam o homem involuntariamente, mantinham-no cativo mesmo que ele se pretendesse livre. (FEBVRE, 2009, p. 292).

No entanto, pelo que parecia uma estranha anomalia, os séculos XVI e XVII testemunharam uma nova onda de vida no cristianismo da Europa Ocidental. Através dele, o cristianismo permeou o vida dessa região de forma mais eficaz e aproximou-se mais dos ideais estabelecidos no Novo Testamento do que em qualquer momento anterior. (LATOURETE, 1965, p. 114; tradução nossa $\left.{ }^{3}\right)$

A Igreja começava a assemelhar-se a uma empresa que, livre da concorrência, distribui os lucros em salários pelos diretores e reduz as vendas a praticamente nada. Mesmo assim, a coerência de comportamento como apanágio de profundo sentimento religioso não era então garantida. A fé do camponês nao esmorecia ao ver no rosto do bispo o suor da caça, nem um jornaleiro pensava que a catedral deixara de ser a casa de Deus apenas por lá ir vender a força de trabalho. (HALE, 1971, p. 184).

Concomitantemente a tais axiomas, compete salientar a ascendente preeminência do arcabouço anticlerical na conjuntura quinhentista europeia, aquando das doutrinas luterana e anglicana rechaçarem explicitamente a sacralidade do pontificado. Por conseguinte, "O anticlericalismo, onipotente, podendo ir da provocação à paixão, quase com certeza afetava a qualidade do envolvimento espiritual dos homens na sua prática religiosa, e um dos alvos era o das propriedades da Igreja." (HALE, 1971, p. 183). Contestava-se amiúde a pujança temporal corroborada pela Santa Sé, aquando do luteranismo e do anglicanismo refutarem o poderio espiritual-ideológico intrínseco ao clero romano. Por conseguinte, o ascendente protestantismo quinhentista antagonizar-se-ia aos intentos mágicos amiúde corroborados pelo catolicismo institucional. A Igreja Católica centenariamente usufruíra do metafísico e das práticas milagreiras sob o intuito de ratificar sua proeminência. Sob tal égide, "Praticamente todas as religiões primitivas são consideradas pelos seus adeptos como meio de obter um poder sobrenatural. [...] A alegação de poderes sobrenaturais foi um elemento essencial na luta da Igreja anglo-saxã contra o paganismo" (THOMAS, 1991, p. 35). Concomitantemente, "Se a distinção entre magia e religião havia sido diluída pela Igreja medieval, os propagandistas da Reforma protestante reafirmaram-na energicamente. [...] os inimigos do catolicismo romano se voltaram contra as conotações mágicas [...] intrínsecas a alguns fundamentos do ritual da Igreja.” (THOMAS, 1991, p. 55). Notoriamente, a Reforma de

3"Yet, by what seemed a strangeanomaly, the sixteen thand seventeenth centuries witnessed a fresh surge of life in the Christianity of Western Europe. Through it Christianity permeated the life of thatregion more effectively and brought it nearer to the ideals set forth in the New Testamentthan in anyearlier time". 
cunho protestante correspondera a uma resposta ideológica às crises espirituais intrínsecas aos quatrocentos e quinhentos.

\begin{abstract}
Os séculos XV e XVI foram decisivos para todos os povos de Deus. Foi um período, sobretudo, crucial para o Ocidente cristão, que conseguira não apenas alcançar as outras culturas do Oikumene, mas iria superá-las. Esses séculos testemunharam o Renascimento italiano, que logo se difundiu para o norte da Europa, a descoberta do Novo Mundo e o início da revolução científica, que teria consequências fatídicas para o resto do mundo. [...] Apesar de seu êxito secular, os europeus se achavam especialmente insatisfeitos com as formas medievais de religião, que não mais respondiam às suas necessidades no admirável mundo novo. Grandes reformadores deram voz a essa inquietação e descobriram novas maneiras de ver Deus e a salvação. Isso evadiu a Europa em dois campos antagônicos - católicos e protestantes - que jamais perderam inteiramente o ódio e desconfiança uns dos outros. (ARMSTRONG, 1994, p. 260).
\end{abstract}

O luteranismo ascende em um ínterim no qual o pontificado corroborava uma hegemonia ideológica na conjuntura europeia, aquando de tal doutrina quinhentista suscitar notórias divergências à pujança exercida pela instituição católica. Concomitante aos axiomas de Quentin Skinner (1996, p. 285), infere-se que a teologia luterana assinalara antagonismos ao tráfico de indulgências, bem como refutara o conjunto de atitudes sociais, políticas e religiosas associadas à Igreja Católica. Divergir-se-ia da ideologia pontifical e do poderio corroborado pelo clero romano. Uma preeminente teologia ascenderia do quinhentista Matinho Lutero, cuja prolongada crise espiritual the propiciara formular uma nova doutrina (SKINNER, 1996, p. 285). Por conseguinte, "A base da nova teologia de Lutero, e da crise espiritual que a precipitou, residia em sua concepção de natureza humana. Lutero vivia obcecado pela ideia da completa indignidade do homem." (SKINNER, 1996, p. 285). Inferese, notoriamente, que o luteranismo refutara o arcabouço tomista concernente à natureza virtuosa atribuída à humanidade pela tradição institucional católica. O teólogo quinhentista corroborava intentos anti-humanistas e ultra agostinianos, contestando a ideologia tomista intrinsecamente vinculada ao arcabouço eclesiástico romano. A religiosidade, por sua vez, aufere imprescindibilidade em seus axiomas, a qual permanece concomitante ao ideário antipontifical.

[Lutero] opõe-se de forma implacável, porém, à tese central e tipicamente humanística de Erasmo, segundo a qual o homem tem à sua frente à possibilidade de utilizar seus poderes racionais para descobrir como Deus quer que ele aja. Lutero insiste, repetidas vezes, em que, nesse contexto, toda capacidade racional do homem é apenas "carnal" e "absurda". (SKINNER, 1996, p. 287). 
Mercê do estudo minucioso do texto grego dos Evangelhos e da crescente acessibilidade da Bíblia originada pela invenção da imprensa, homens conscienciosos verificaram que muito daquilo que era típico da Igreja contemporânea tinha fraco apoio nos Evangelhos [...]. O estudo do texto grego levou a dar-se uma importância maior ao texto literal da Bíblia, em oposição ao método alegórico e a outros métodos de interpretação vulgarizados na Idade Média. [...] O acolhimento do texto literal da Bíblia pelos humanistas significou rejeição do método escolástico de interpretação que dominara durante tanto tempo a vida intelectual da Igreja. [...] $\mathrm{Na}$ filosofia dos reformadores, São Paulo e Santo Agostinho eram mais importantes do que Aristóteles e Platão. (GREEN, 1984, p. 130-131).

A proeminência do arcabouço metafísico auferira notoriedade na Inglaterra quinhentista, axioma ratificado pelas conjecturas religiosas suscitadas na Utopia de Thomas More (2004). A religiosidade permanece explicitamente intrínseca a tal conjuntura. Intentos de cunho anticlerical, por sua vez, corroborariam ascendente preeminência, aquando de advir institucionalmente o anglicanismo. Primariamente suscitado por Henrique VIII (1509-1547), tal doutrina auferira ratificações procedentes da monarca Elizabeth I (1558-1603). Ambos os regentes Tudor visaram subordinar a conjuntura eclesiástica inglesa ao arquétipo estatal em ascendente fortalecimento. Sob tal égide, "[...] o poder real, muito mais concreto que o imperial no século XIV, só se consolidou por meio de uma história de disputas com a Igreja e com o Império, em que os reis enfrentaram cada adversário separadamente. No caso inglês, [...] restava, como rival, o poder do clero." (KRITSCH, 2004, p. 110). Infere-se, notoriamente, que política e religião permaneciam intrinsecamente vinculadas na conjuntura inglesa. Díspar do ideário ultra agostiniano corroborado por Lutero, a quinhentista doutrina anglicana vincular-se-ia intrinsecamente ao intento de antagonizar-se à pujança temporal pontifical nas ilhas inglesas. Por conseguinte, infere-se que "Henrique VIII e Elizabeth I não poderiam ser comparados aos grandes reformadores do século XVI. A sua obra religiosa, amplamente inspirada pelo desejo de subordinar a vida eclesiástica aos interesses de Estado, não teria sobrevivido se o Papado não houvesse sido outrora profundamente desconsiderado nas Ilhas Britânicas" (DELUMEAU, 1981, p. 137). Compete ao historiógrafo, por conseguinte, empreender análises que distinguem ambas as doutrinas quinhentistas, averiguando assiduidades e alomorfias entre luteranismo e anglicanismo.

\section{Assiduidades e alomorfias doutrinárias}

Embora heterodoxias amiúde tenham ascendido na conjuntura europeia, o catolicismo romano auferira o cunho de doutrina hegemônica no transcorrer de centúrias. Exercia-se uma 
implícita hegemonia ideológica no ínterim ocidental procedente do pontificado, o qual suscitara antagonismos ante as ascendentes heresias (FALBEL 1976). Notoriamente, corrobora-se que tal instituição monopolizara secularmente as categorias intelectuais, aquando de restringir o advento de uma cultura autônoma alternativa (BITTAR; AMARILIO, 2012). A religiosidade institucionalizada pela Santa Sé constituía um preeminente sistema ideológico, integrando eminentemente o quotidiano europeu (TOUCHARD, 2004). Por conseguinte, o catolicismo procedia dos discípulos cristãos, aquando do pontificado constituir proeminente potentado espiritual e temporal na conjuntura ocidental. $\mathrm{O}$ papado suscitava notório poder secular, influindo na conjuntura principesca dos Estados europeus. Embora corrobore axiomas precedentes, o protestantismo quinhentista suscitaria explícitas divergências ante tal instituição hegemônica, cujas ascendentes doutrinas heterodoxas corroborariam notórias disparidades ideológicas. Notoriamente, compete ao historiógrafo apreender a heterogeneidade das doutrinas protestantes, as quais se tornariam determinantes na conjuntura procedente ao quinhentos. Um ascendente antagonismo permaneceria posteriormente verificado entre protestantismo e catolicismo, cujas divergências implicariam em influxos econômicos e socioculturais na conjuntura europeia.

[...] o impacto de homens como Lutero, Calvino e Zuínglio não pode ser corretamente avaliado. $\mathrm{O}$ molde particular da sua mente, as suas profundas emoções e ideias bem definidas, tudo isso levou a Reforma como movimento a seguir o trilho que seguiu e a quebrar a unidade dos cristãos. Ao mesmo tempo, os reformadores estavam a dar respostas a um descontentamento generalizado relativamente à religião contemporânea. [...] O papa transformara-se num príncipe italiano, muito mais preocupado com a expansão do poder temporal do Papado com que com os interesses da Igreja universal. [...] Dum modo geral, a religião tornara-se mais mecânica e materialista do que fora antes. [...] O sistema de indulgências tinha tido a sua origem no tempo das Cruzadas, como um meio das pessoas compensarem a sua incapacidade de tomar parte numa cruzada e não deixarem, por isso, de garantir o prometido perdão dos pecados, mediante um pagamento em dinheiro à Igreja. [...] Foi-se dando cada vez menos importância à penitência implicada na indulgência e mais importância ao perdão automático que o pagamento do dinheiro garantia. A religião andava, assim, impregnada de formas materiais e mecânicas. (GREEN, 1984, p. 123-124, 128)

Embora corroborem tautocronia cronológica e ratifiquem a proeminência do metafísico, as doutrinas luteranas e anglicanas auferem notórias disparidades ideológicas. Ambos os ideários suscitam antagonismos ao arcabouço temporal e espiritual intrínseco ao pontificado quinhentista, bem como ratificam intentos eminentemente teocêntricos. Embora alomorfias concernentes aos fundamentos da fé permanecerem notórias, a espiritualidade 
auferira imprescindibilidade em ambos os ideários, os quais suscitaram reações ativas ao catolicismo (GREEN, 1984, p. 123). No entanto, simplórias apreensões historiográficas amiúde empreendem irrisórias aproximações concernentes a tais doutrinas, aquando de homogeneizá-las em categorias uniformes. Sob tal égide, diverge-se das generalizações implicitamente corroboradas por Lemos e Alves (2013), os quais suscitam o protestantismo uniformemente. Compete ao historiógrafo, por sua vez, atentar-se às alomorfias explicitamente intrínsecas, em que a história comparada torna-se imprescindível a fim de propiciar um intento epistemológico. Homogeneizações auferem um cunho irrisório para a profícua apreensão das especificidades das doutrinas protestantes quinhentistas, atribuindo-se ao pesquisador averiguar as disparidades e assiduidade intrínsecas às doutrinas luteranas e anglicanas. Primariamente, compete salientar que os axiomas intrinsecamente vinculados a Lutero aufeririam ascendente proeminência em âmbito germânico, bem como suscitara procedentes influxos no continente europeu (SKINNER, 1996). Antagonicamente, por sua vez, o anglicanismo albergara influxos regionais, cujos axiomas notoriamente restringiram-se aos domínios ingleses. Ademais, infere-se que o luteranismo suscitou a efetiva fragmentação da unidade cristã preeminente em âmbito europeu, influxo díspar do corroborado pelo reformismo de cunho anglicano.

Ademais, o reformismo luterano veiculara-se notoriamente ao intuito de edificar uma nova teologia, usufruindo do arcabouço bíblico a fim de divergir da hermenêutica institucional romana (SKINNER, 1996). Efetivamente, o luteranismo conferira imprescindibilidade à contestação ideológica da hegemônica interpretação bíblica corroborada pelo pontificado. Sob tal égide, "O cerne da teologia de Lutero reside em sua doutrina da justificação sola fide, 'pela fé somente'. [...] O fiel em qualquer ocasião é visto como simuljustus et peccator - a um só tempo, pecador e justificado. Seus pecados jamais são apagados, mas sua fé garante que deixe de pesar contra ele.” (SKINNER, 1996, p. 290). A fé e a Bíblia auferem proeminência na teologia luterana, a qual contesta o ideário católico concernente à glorificação das obras humanas. Por conseguinte, compete salientar que o luteranismo suscitara uma doutrina que rompia explicitamente com os preceitos procedentes do catolicismo, aquando de conferir proeminência a alternativas apreensões bíblicas. Corrobora-se que Lutero notoriamente contestava a hermenêutica católica, bem como propunha uma nova teologia a fim de suprimi-la. Por conseguinte, infere-se que "[Lutero] não só achou insuficiente a vida espiritual da Igreja como adiantou vigorosamente a conclusão de que a doutrina em que ela assentava era parcialmente verdadeira." (GREEN, 1984, p. 129). Antagonicamente, o anglicanismo não suscitara notórias contestações à ideologia católica, 
usufruindo de ideários procedentes da romana Santa Sé. Ademais, distintamente do arcabouço pontifical, o luteranismo ratificara a impossibilidade do homem em empregar sua razão a fim de propiciar sua salvação e apreender Deus. Tal axioma notoriamente distingue-se do anglicanismo quinhentista, para quem a compreensão humana torna o indivíduo apto a obter a salvação.

O impulso inicial dado ao pensamento anglicano no século XVI foi uma crença confiante em Deus, como criador do mundo, que, apesar de caído, era inteligível para a compreensão humana. Do bíblico, patrística e medieval, a liturgia anglicana expressou o louvor de Deus, principalmente no uso diário do livro de Salmos e de cânticos como Benedicite e Te Deum. Embora inicialmente a Igreja reformada da Inglaterra se entendeu como uma forma de protestantismo, a visão do equilíbrio do trabalho de Deus na criação e na história humana era um pouco distintivo, dando à sua opinião um caráter um pouco menos antropocêntrico. (HUYSSTEEN, 2003, p. 119-120; tradução nossa).

O propósito do Velho Testamento, diz-nos agora Lutero, consiste em "ensinar o homem a conhecer-se", de modo que "possa ele reconhecer sua incapacidade de praticar o bem e possa desesperar-se ante essa incapacidade" - chegando a um desespero análogo ao que o próprio Lutero sentira, de forma tão aguda. [...] Já o Novo Testamento, em contraste, tem por propósito reconfortar-nos que, embora não tenhamos capacidade de atingir a salvação "tentando cumprir todas as obras da lei", podermos, porém, atingi-la "rápida e facilmente por meio da fé". (SKINNER, 1996, p. 291).

Concomitantemente, infere-se que o quinhentos alberga um ínterim no qual o poderio da instituição monárquica gradualmente divergiria da pujança temporal corroborada pelo pontificado (GREEN, 1984). O ideário de cunho anglicano ascendera sob uma conjuntura na qual se suscitaria o ascendente fortalecimento do arquétipo estatal inglês. Tal centúria alberga um ínterim de notória consolidação da pujança principesca (STRAYER, 1986). Um explícito antagonismo de poderes ascenderia entre Santa Sé e monarquia inglesa, aquando da religião vincular-se a tal disputa estadista. Concomitante à intitulação de chefe supremo da Igreja inglesa, o rei rechaçaria espiritualmente a pujança pontifical, refutando a proeminência do papado na mediação entre o âmbito terreno e metafísico (JONES, 2005, p. 349). Infere-se, por conseguinte, que o advento do anglicanismo vincular-se-ia intrinsecamente a intentos de cunho político, aquando de não visar edificar uma nova ideologia que suprimiria universalmente a doutrina católica. Política e religião permaneceram veiculadas ao advento do ideário anglicano, o qual efetivamente constituiu uma via média entre protestantismo e catolicismo (CALVANI, 2005). Diverge-se, por conseguinte, dos axiomas corroborados por A. Wolkmer (2005), para quem o quinhentos alberga um ínterim de secularização política. 
Efetivamente, a hierarquia católica não permanecera rechaçada, aquando de um arcabouço calvinista permear o anglicanismo. Por conseguinte, tal doutrina não implicou na edificação de uma nova teologia, mas consistiu no resultado de uma hibridização religiosa.

O papa mantinha o seu poder nos países estrangeiros por intermédio de núncios e legados que defendiam os seus interesses; era senhor duma considerável jurisdição de recurso, bem como dum imenso padroado. O choque entre o poder universal do papa e a autoridade nacional do monarca era claramente inevitável. [...] enquanto os reis de Espanha e de França descobriram que podiam chegar a acordos com o papa em benefício dos seus próprios interesses, os reis da Inglaterra e da Suécia entenderam que a negação da autoridade pontifícia era quase um corolário da manutenção e extensão do seu poder central. (GREEN, 1984, p. 129).

\section{Considerações finais}

O mundo contemporâneo é moldado pelas religiões: a "guerra contra o terror", o design inteligente, as campanhas contra o aborto e as pesquisas com células tronco, os conflitos e as guerras no Oriente Médio, enfim, a lista é significativa. Dificilmente passa um dia em que não sejamos informados, pela TV, pelos jornais ou pela internet, acerca de alguma manifestação de origem religiosa, ligada a práticas, conflitos ou identidade religiosos. Para entender o mundo contemporâneo, bem como o passado, precisamos de uma compreensão mais complexa da religião. Em todos os contextos históricoculturais a religião é parte integrante de outros aspectos da vida social. A religião é tanto um conjunto de ideias e crenças que as pessoas podem desenvolver como também a estrutura para suas vivências e práticas diárias. $\mathrm{O}$ estudo da religião a partir da história cultural nos permite compreender como a religião pode ser um elemento importante na análise de vários grupos sociais a partir de suas formas de sociabilidade, de contato com a alteridade e de como esses grupos se apropriam de uma realidade que é social. (ANDRADE, 2013, p. 09-10).

Notoriamente impulsionada pelas fainas procedentes dos decênios finais do novecentos, a historiografia concernente às religiões, crenças e religiosidades constitui preeminente âmbito da ciência humana. Intrinsecamente vinculada às mentalidades, albergariam preeminentes campos historiográficos. Concomitantemente, tais domínios auferem imprescindibilidade para a edificação de paradigmas, bem como moldam culturalmente idiossincrasias sociais. Sob tal égide, infere-se que "A religião representaria o resultado da elaboração discursiva de uma elite institucional que estabelece as chaves interpretativas do dogma, dominando a tecnologia da escritura, a qual outorga às suas produções a qualidade de legado transcendental.” (ANDRADE, 2013, p. 11). As doutrinas luteranas e anglicanas inserem-se em tal arquétipo concernente às religiões hodiernas, cuja gênese primariamente remonta ao ínterim quinhentista. Embora notoriamente corroborem 
maximizações ideológicas no transcorrer das centúrias, a profícua apreensão de seus preceitos demanda de exames intrínsecos à conjuntura de edificação. Compete ao historiador suscitar as disparidades intrínsecas a tais doutrinas, bem como transcender as recorrentes homogeneizações historiográficas.

\section{REFERÊNCIAIS}

ANDRADE, S. R. História das religiões e religiosidades: uma breve introdução. In: MARANHÃO Fo, E. M. de A. (Org.). (Re)conhecendo o sagrado. Reflexões teóricometodológicas dos estudos de religiões e religiosidades. São Paulo: Fonte Editorial, 2013, p. 09-28.

ARIÈS, P.; DUBY, G. História da vida privada. Da Renascença ao Século das Luzes. São Paulo: Companhia das Letras, 2009.

ARMSTRONG, K. Uma história de Deus: quatro milênios de busca do judaísmo, cristianismo e islamismo. São Paulo: Companhia das Letras, 1994.

BITTAR, M.; AMARILIO, F. Jr. História e Filosofia da Ciência. In: SOUZA, M. de F. M. de.; MORAIS, A. S. de. (Orgs). Origem e evolução do conhecimento - OEC. Universidade Federal do Oeste do Pará - UFOPA, 2012, p. 14-30.

BRAUDEL, F. A longa duração. In: Fernand Braudel. História e Ciências Sociais. Lisboa: Editorial Presença, 1990, p. 07-39.

CALVANI, C. E. B. Anglicanismo no Brasil. REVISTA USP, São Paulo, n. 67, set./nov., 2005, p. 36-47.

CHESNEAUX, J. Devemos fazer tábula rasa do passado? Sobre a história e os historiadores. São Paulo: Editora Ática, 1995.

DELUMEAU, J. Nascimento e afirmação da reforma. São Paulo: Pioneira, 1981.

FALBEL, N. Heresias medievais. São Paulo: Editora Perspectiva, 1976.

FEBVRE, L. O problema da incredulidade no século XVI. A religião de Rabelais. São Paulo: Companhia das Letras, 2009.

GREEN, V. H. H. Renascimento e Reforma: a Europa entre 1450 e 1660. Lisboa: Publicações Dom Quixote, 1984.

HALE, J. R. A Europa durante o Renascimento: 1480-1520. Lisboa: Editorial Presença, 1971.

HUYSSTEEN, J. W. V. V. Encyclopedia of scienceandreligion. $2^{\circ}$ ed. New York: Thomson Gale, 2003. 
JONES, L. Encyclopedia of Religion. $2^{\mathrm{a}}$ ed. Thomson Gale, v. 01, 2005.

KRITSCH, R. Rumo ao estado moderno: as raízes medievais de alguns de seus elementos formadores. Rev. Sociol. Polít., Curitiba, 23, nov., 2004, p. 103-114.

LATOURETE, K. S. ChristianityThroughthe Ages. New York: Harper \& Row, 1965.

LEMOS, D L.; ALVES, A. A quebra do elo: as consequências da reforma protestante para o fim das mediações sacerdotal. DIÁL OGOS - Revista de Estudos Culturais e da Contemporaneidade, n. 8, fev./mar., 2013, p. 135-162.

LOVEJOY, A. O. Reflexiones sobre la historia de las ideas. Prismas, Revista de História Intelectual, $n^{\circ}$ 4, 2000, p. 127-141.

MORE, T. Utopia. Brasília: Editora Universidade de Brasília, 2004.

SKINNER, Q. As fundações do pensamento político moderno. São Paulo: Companhia das Letras, 1996.

STRAYER, J. R. As origens medievais do Estado Moderno. Lisboa: Gradiva, 1986.

THOMAS, K. Religião e o declínio da magia. São Paulo: Companhia das Letras, 1991.

TOUCHARD, J. Historia de las ideias políticas. España: Tecnos, 2004.

WOLKMER, A. Cultura jurídica moderna, humanismo renascentista e reforma protestante. Revista Sequência, $n^{\circ}$ 50, jul. 2005, p. 09-27.

\section{Como referenciar este artigo}

MULZA, Giovana Eloá Mantovani. Doutrinas quinhentistas: assiduidades e alomorfias entre luteranismo e anglicanismo. Rev. Sem Aspas, Araraquara, v. 6, n. 2, p. 135-146, jul./dez., 2017. e- ISSN: 2358-4238.

Submetido em: 17/12/2017

Aprovado em: 23/12/2017 